\title{
Schools under mandatory testing can mitigate the spread of SARS-CoV-2
}

Citation for published version (APA):

Isphording, I. E., Diederichs, M., van Ewijk, R., \& Pestel, N. (2021). Schools under mandatory testing can mitigate the spread of SARS-CoV-2. ROA. ROA Research Memoranda No. 008 https://doi.org/10.26481/umaror.2021008

Document status and date:

Published: 22/11/2021

DOI:

10.26481/umaror.2021008

Document Version:

Publisher's PDF, also known as Version of record

\section{Please check the document version of this publication:}

- A submitted manuscript is the version of the article upon submission and before peer-review. There can be important differences between the submitted version and the official published version of record.

People interested in the research are advised to contact the author for the final version of the publication, or visit the DOI to the publisher's website.

- The final author version and the galley proof are versions of the publication after peer review.

- The final published version features the final layout of the paper including the volume, issue and page numbers.

Link to publication

\footnotetext{
General rights rights.

- You may freely distribute the URL identifying the publication in the public portal. please follow below link for the End User Agreement:

www.umlib.nl/taverne-license

Take down policy

If you believe that this document breaches copyright please contact us at:

repository@maastrichtuniversity.nl

providing details and we will investigate your claim.
}

Copyright and moral rights for the publications made accessible in the public portal are retained by the authors and/or other copyright owners and it is a condition of accessing publications that users recognise and abide by the legal requirements associated with these

- Users may download and print one copy of any publication from the public portal for the purpose of private study or research.

- You may not further distribute the material or use it for any profit-making activity or commercial gain

If the publication is distributed under the terms of Article $25 \mathrm{fa}$ of the Dutch Copyright Act, indicated by the "Taverne" license above, 


\section{Maastricht University $\$$ ROA}

Schools under mandatory testing can mitigate the spread of SARS-CoV-2

Ingo E. Isphording Marc Diederichs

Reyn van Ewijk

Nico Pestel

\section{ROA Research Memorandum}

ROA-RM-2021/8

Researchcentrum voor Onderwijs en Arbeidsmarkt | ROA Research Centre for Education and the Labour Market / ROA 


\title{
Schools under mandatory testing can mitigate the spread of SARS-CoV-2
}

\author{
Ingo E. Isphording \\ Marc Diederichs \\ Reyn van Ewijk \\ Nico Pestel
}

ROA-RM-2021/8

November 2021

Research Centre for Education and the Labour Market Maastricht University P.O. Box 616, 6200 MD Maastricht, The Netherlands

$\mathrm{T}+31433883647$

secretary-roa-sbe@maastrichtuniversity.nl

www.roa.nl

ISSN: 2666-8823 


\section{Abstract}

\section{Schools under mandatory testing can mitigate the spread of SARS-CoV-2*}

We use event-study models based on staggered summervacations in Germany to estimate the effect of school re-openings after the summer of 2021 on the spread of SARS-CoV-2. Estimations are based on daily counts of confirmed coronavirus infections across all 401 German counties. Our results are consistent with mandatory testing contributing to containment of cases by uncovering otherwise undetected (asymptomatic) cases. Case numbers in school-aged children spike in the first week after the summer breaks but then turn not significantly different from zero. Case numbers in prime-aged age groups gradually decrease after school re-openings, arguably as a result of detected clusters through the school testing. The age group 60+ remains unaffected by the school reopenings. We conclude that the combination of mandatory testing and compulsory school attendance can provide an unbiased and near-complete surveillance of the pandemic. Thus, under certain conditions open schools can play a role in containing the spread of the virus. The trade-off between reducing contacts and losing an important monitoring device has to be taken seriously when re-considering school closures as a nonpharmaceutical intervention under the current circumstances.

JEL classification: I12, I18, I28

Keywords: COVID-19, schooling, education, Germany

Ingo E. Isphording

Institute of Labor Economics (IZA)

Schaumburg-Lippe-Str. 5-9

D-53113 Bonn

Germany

isphording@iza.org

and CESifo

Reyn van Ewijk

Johannes Gutenberg University Mainz

Chair of Statistics \& Econometrics

Johannes-v.-Müller-Weg 2

D-55128 Mainz

Germany

vanewijk@uni-mainz.de

\author{
Marc Diederichs \\ Johannes Gutenberg University Mainz \\ Chair of Statistics \& Econometrics \\ Johannes-v.-Müller-Weg 2 \\ D-55128 Mainz \\ Germany \\ diederichs@uni-mainz.de \\ Nico Pestel \\ Maastricht University \\ ROA \\ P.O. Box 616 \\ NL-6200 MD Maastricht \\ The Netherlands \\ n.pestel@maastrichtuniversity.nl \\ and IZA
}

\footnotetext{
* The authors declare no competing interest. We are grateful to Pooja Singh and Khalid Imran who provided excellent research assistance.
} 


\section{Introduction}

The SARS-CoV-2 pandemic is far from over yet. More than one and a half years after its global onset in early 2020, the spread of the novel coronavirus continues to cause large numbers of new infections, hospitalizations and deaths worldwide. At the same time, the pandemic situation has substantially changed over the last months due to several major "game changers": about half of the world's population has been vaccinated against the disease, yet with vaccination rates being much higher in rich compared to poor countries, and vaccines being unapproved for children until very recently. ${ }^{1}$ Further, more contagious variants of SARS-CoV-2 ("Delta" strain) have appeared, lowering the effectiveness of vaccines (Tang et al., 2021). Finally, new technologies, especially large-scale rapid testing, provide new measures to help contain the spread of the virus. Taken together, these factors once more bring schools to the center of the public debate: vaccination rates among adolescents lag behind those of adults, as population-wide vaccination campaigns among this age group only started recently. Meanwhile, vaccination remains mostly unavailable to those younger than 12 years of age. This leaves children vulnerable to infection and through spillovers may increase infection rates among their families and populations at large. As a result, on 31 October 2021, schools in 64 countries worldwide remained fully or partially closed due to pandemic concerns. ${ }^{2}$

Up until now, there is no consensus about the role of schools in transmitting the virus. Correlational studies relying on before/after comparisons indicate zero to large effects on case numbers after school openings. Yet, these studies lack a valid identification of the causal effect of open schools. Studies employing plausible quasi-experimental designs provide a more consistent picture. Under strict hygiene rules as well as testing and quarantining regimes, open schools contribute nothing or only little to rising case numbers. Yet, it is questionable whether the existing evidence stemming from settings before the spread of new variants, and with low or zero vaccination rates among adults, extrapolates well to the current situation 3

Against this background, we provide the first causal evidence on the impact of opening schools in a situation with the dominant "Delta" strain and substantial vaccination rates. We do so by replicating the empirical approach by lsphording et al. (2021) with the most recent data on official daily case counts by age group across all 401 German counties (Kreise). To identify a causal effect of school openings, we exploit the staggered timing of summer breaks across German federal states with schools closing in June/July and re-opening in August/September 2021 after having been fully closed for about six weeks. We implement an event study design in which we compare changes in newly confirmed cases in re-opening states relative to the end of summer breaks. We keep mobility patterns measured by Google Mobility Reports statistically constant between treatment and control group. This approach implies that we compare against the counterfactual situation of summer breaks ending, but without students returning to in-class teaching, i.e., adopting distance learning arrangements.

Our results show that schools did not contribute to the overall growth in case numbers. Further, our results are consistent with the hypothesis that the combination of mandatory

\footnotetext{
${ }^{1}$ See: https://ourworldindata.org/covid-vaccinations (last accessed: 11 November 2021).

${ }^{2}$ https://en.unesco.org/covid19/educationresponse last accessed on 12 November, 2021.

${ }^{3}$ We summarize the existing literature in Section 2.1
} 
testing in schools and compulsory school attendance contributed to a containment of cases after the summer breaks. Compared to control states, we observe an initial spike in detected cases in the first two school days among school-aged students, displaying the detection of clusters that remained undetected during the summer breaks. Prime-aged population groups experience a gradual decrease after school re-openings relative to control states, arguably due to spillovers from the early detection and quarantining. Vulnerable age groups aged 60 and above are entirely unaffected by the school re-openings.

Our results have important implications for the design of future non-pharmaceutical interventions to mitigate the spread of SARS-CoV-2, but also comparable future diseases. School closures were one of the most widely used non-pharmaceutical interventions during the first waves of the pandemic, with more than 1.6 billion students globally being affected at peak. School closures produced substantial direct and indirect costs in learning losses (Engzell et al., 2021), children's health and mental well-being (Viner et al., 2021), parental labor market outcomes (Heggeness, 2020) and domestic violence (Leslie and Wilson, 2020). Moreover, these costs are borne primarily by low socio-economic status households, increasing inequality (Jang and Yum, 2020). Yet, empirical evidence on their effectiveness is sparse, ambiguous, and based on data before the aforementioned "game-changers". Our results imply that schools under a set of hygiene rules and mandatory testing remain a safe place. These hygiene rules include regular airing or the use of air filters and mandatory mask-wearing. Mask mandates were a crucial feature of hygiene concepts in place during the weeks after the summer break, but were relaxed or abandoned some weeks later by some federal states. Further, the combination of compulsory school attendance and mandatory rapid testing provides an important, unbiased surveillance of the scope of the pandemic which is crucial for the early detection and quarantining of clusters. The argument of a crucial role of rapid mandatory testing has been made before by complementary simulation studies by Mohring et al. (2021) and Gabler et al. (2021). Taken together, our results therefore strongly suggest not to consider school closures as a preferred non-pharmaceutical intervention under the current circumstances.

\section{Background}

\subsection{Schools and SARS-CoV-2}

School closures have been an effective strategy against earlier pandemics through the mechanical reductions in social contacts (e.g., influenza, see Cauchemez et al., 2009, Bin Nafisah, 2018), yet they come with substantial costs in learning, future wages, physical and mental health, as well as substantial spillovers to parental labor supply and well-being. Werner and Woessmann (2021) provide a comprehensive review of this "legacy" of Covid-19 on education. These costs have to be carefully weighed against the positive effects of school closures in mitigating the spread of the virus (Adda, 2016). Whether or not school closures are an effective non-pharmaceutical intervention in the case of SARS-CoV-2 is debated heatedly.

Early evidence tracing specific outbreaks to school environments drew public attention to the role of schools (Stein-Zamir et al., 2020). Contact-tracing studies in school environments confirmed that children are not exempted from transmitting the virus (Heavey et al., 2020; 
Fontanet et al. 2020; Macartney et al., 2020). First systematic evidence was mainly relying on time-series data and simple overtime comparisons. A systematic review by Walsh et al. (2021) describes a large heterogeneity in results, with half of the studies documenting significantly reduced community transmission, while the remaining studies report no association. A similar heterogeneity is displayed in prospective modelling and simulation studies. Again, results range from school closures being effective mitigating policies (Panovska-Griffiths et al., 2020) to null results (Chang et al., 2020; Davies et al., 2020). Some simulation studies highlight the role of distancing measures, e.g., small group teaching, in containing outbreaks in schools (Lee et al., 2020).

A potential caveat of most of the association and simulation studies is that the underlying overtime variation does not allow for a causal identification of the effect of schools. In most cases, underlying empirical approaches boil down to before/after comparisons, with the main shortcoming that other simultaneous factors are not controlled for. Yet, proper quasi-experimental approaches are difficult to come by, with the Covid-19 crisis having a near-universal and worldwide influence on every aspect of life 4 A number of notable exceptions apply valid identification strategies to estimate the causal effect of school closures and re-openings. Several studies apply panel regressions based on longitudinal variation across U.S. counties. Chernozhukov et al. (2021) estimate that cases and deaths in counties with in-person or hybrid teaching substantially increased. The effect was found to be stronger for counties without any mask mandate for staff. Goldhaber et al. (2021) find modest positive effects of school re-openings on case numbers in the U.S. states of Washington and Michigan, primarily when pre-existing case numbers are high. Harris et al. (2021) find no effect for school re-openings when case numbers are low. Results for higher levels of case numbers are inconclusive. Differently from these papers, Courtemanche et al. (2021) focus on the state of Texas, where schools re-opened under hardly any precautionary measures and under high levels of community spread. Their estimates indicate a strong positive effect on case numbers and fatalities in the weeks after the school re-openings. In accordance with these very different effect patterns, Ertem et al. (2021) employ event-study designs and find no effect of re-opening schools in the North of the U.S., but significant and sustained effects in the South, indicating a role of behavioral differences.

For countries beyond the U.S. Vlachos et al. (2021) compare students of upper secondary schools in Sweden during the first wave who moved to online instruction with students of lower secondary schools which remained open. Parents of in-school students experience a small increase in confirmed infections. Stronger effects are found for directly exposed teachers. For Japan, Fukumoto et al. (2021) find no evidence for higher case numbers after school re-openings based on a matching approach on the municipality level. Two studies apply quasiexperimental approaches for Italy. Alfano et al. (2020) compare early re-opening schools in Bolzano with a synthetic control group of comparable Italian provinces, finding substantially higher case numbers after school re-openings, yet offering no discussion of the circumstances of school re-openings. Amodio et al. (2021) use locally delayed re-openings of single schools on georeferenced cases in Sicily to identify a modest increase of cases by $2 \%$ two weeks after the school opening.

\footnotetext{
${ }^{4}$ See also the discussion on why Covid-19 is a poor natural experiment by Bacher-Hicks and Goodman (2021).
} 
Finally, and similar to the present study, Isphording et al. (2021) and von Bismarck-Osten et al. (2021) apply event-study designs to the staggered summer breaks in Germany to compare re-opening states with states that are still in their summer breaks. They do not find evidence for increased case numbers after summer breaks. Estimates by lsphording et al. (2021) rather point to slight and insignificant reductions in case numbers, potentially attributed to strict hygiene measures and changes in parental behavior.

Taking stock of the quasi-experimental evidence, we conclude that the effect of school re-openings is very context-specific. Yet, while far from being unambiguous, the overwhelming part of the literature suggests that schools could be re-opened safely in 2020 when conditions such like hygiene rules, distance measures, mask-wearing and testing were in place. Such strategies have been comprehensively described and discussed by scientists and practitioners alike, among others in Willyard (2021) and Buntin and Gavulic (2020). Yet, several factors have changed since 2020. Critics object that new and more aggressive variants of the virus may change the picture. Early media reports on the new "Delta" variant suggested that children may be particularly vulnerable to this new strain.5 More comprehensive evidence was less conclusive about the particular impact on children (Brookman et al., 2021). At the same time, other factors have changed, too. Vaccination rates in many Western countries are now substantial, also among older school-aged children. Scientific evidence on the virus' transmission has led to more targeted mitigation measures, such as the application of air filters in classrooms. Given these changes, it appears important to re-analyze the effect of school re-openings under the new contextual setting.

\subsection{Testing, school hygiene measures and vaccinations}

During our observation period, while in general having autonomy about school policy, German states implemented similar and comparable measures against the spread of SARS-CoV-2 in schools. These measures comprised of regular testing, quarantining of positive cases and suspects for infection, as well as general hygiene measures.

From the end of summer breaks in 2021 on, both students and teachers were tested regularly (two or three times per week) using rapid antigen tests. In the weeks immediately after the re-opening of schools after the summer break, testing was more frequent, up to daily depending on the state. Testing was mandatory, and opt-out was not an option except for those who had been vaccinated or infected earlier 6 Individuals with positive test results were isolated and had to undergo a PCR test in order to confirm whether the rapid antigen test was a true positive. In some states, namely North Rhine-Westphalia and later Bavaria, pooled PCR tests were used to jointly test entire classes and to identify single positive cases only after. States further decided on a common set of quarantine rules. Positive tests led to immediate quarantining of the positively tested student. Peers, class members or seat neighbors, who are

${ }^{5}$ See, e.g., https://au.news -yahoo.com/covid-wards-full-of-children-as-uk-pandemic-explodes-c 53207113. html or https://www . dailymail.co.uk/news/article-9106509/Coronavirus-London-childrens-hos pital-consultanthtml (last accessed: 11 November 2021).

${ }^{6}$ Only in Thuringia, mandatory testing was abandoned after a few weeks; testing regimes were coupled to county incidence rates. 
suspect to having potentially been infected, too, go into a quarantine which could be shortened with a negative test after five days.

Besides testing, a number of additional measures were kept in place. All states required that classrooms were aired frequently by opening windows, or by means of mobile or fixed air filters. Mask-wearing remained mandatory in the period immediately after the summer break, with mask regulations becoming heterogeneous between federal states, often tied to incidence numbers.

During the observation period, schools remained open in all federal states. Full or partial school closures were planned for case numbers reaching pre-defined thresholds, which did not happen during the observation period.

Population-wide vaccination rates in Germany increased over the observation period to $65 \%$ being fully vaccinated (with an additional $3 \%$ having received a first dose), which reflects a lower bound due to imperfect registration systems.7] Among children, vaccination rates remained markedly lower. An official advice by the German Standing Vaccination Committee (STIKO) to vaccinate those aged 12-17 was given on 16 August 2021. By the first week of October, the rate of fully vaccinated among this group remained at around $35 \%$. Vaccinations among younger children played no role during the observation period.

\subsection{Summer breaks in Germany}

In Germany, the timing of the six-week-long summer breaks vary across states since the 1950s. This varying schedule is supposed to avoid traffic congestion as well as excess demand for holiday accommodation in tourist regions if the entire German population went on holidays at the same time. The staggered timing of summer vacation periods follows a long-term scheduling (currently up to 2024) and is decided by the Standing Conference of the Ministers of Education and Cultural Affairs (Kultusministerkonferenz, KMK), a consortium of state ministers responsible for education and schooling 8 Importantly, throughout the SARS-CoV2 pandemic, the long-term scheduled summer break schedules in 2020 and 2021 remained unaffected by regional differences in case numbers.

Figure 1 shows the school starting dates after the summer breaks in 2021 across German states ranging from early-August to mid-September 2021. Only on two days at the end of July 2021, schools across all German states were closed simultaneously due to summer breaks. Therefore, we can exploit the exogeneity in the staggered timing of school re-openings after summer vacations across German states for causal identification of their impact on confirmed case numbers.

\footnotetext{
${ }^{7}$ See www.rki.de/DE/Content/InfAZ/N/Neuartiges_Coronavirus/Daten/Impfquoten-Tab.html (last accessed: 11 November 2021).

${ }^{8}$ See https://www.kmk.org/service/ferien.html for details (last accessed: 11 November 2021).
} 

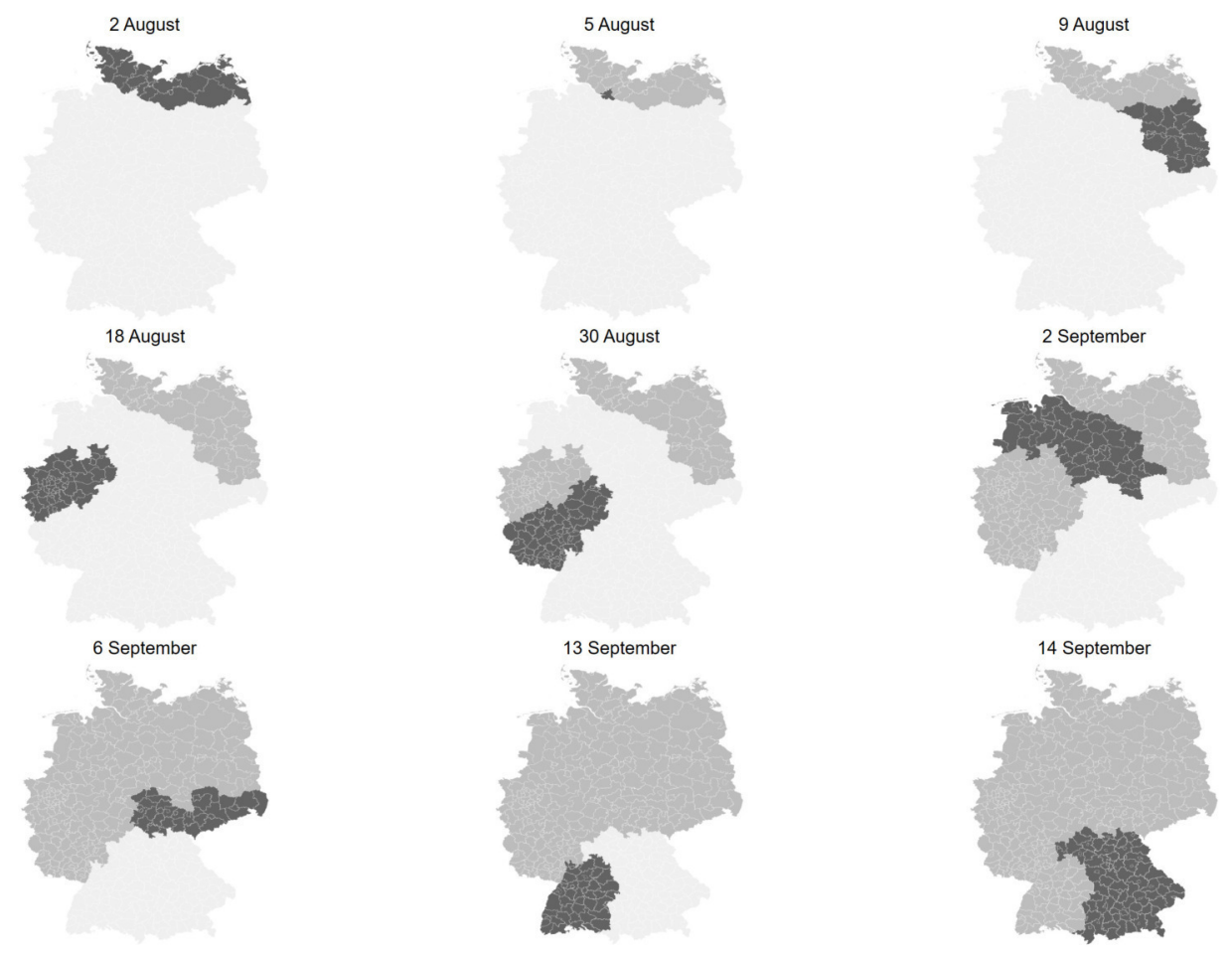

Figure 1: School Opening Dates after Summer Vacation 2021 in Germany

Note: This graph shows a map of German counties and highlights counties in states by the date of school opening after summer vacation 2021. Counties (states) highlighted in dark gray start the new school year on the respective date, while light gray indicates that they are still on summer vacation and medium gray indicates that they had already re-opened schools at an earlier date. School re-opening dates are as follows, 2 August: Mecklenburg-Vorpommern, Schleswig-Holstein, 5 August: Hamburg, 9 August: Berlin, Brandenburg, 18 August: North Rhine Westphalia, 30 August: Hessia, Rhineland-Palatinate, and Saarland, 2 September: Lower Saxony, Bremen, and Saxony-Anhalt, 6 September: Saxony and Thuringia, 13 September: Baden-Wuerttemberg, 14 September: Bavaria. Source: KMK.

\section{Data and empirical strategy}

\subsection{Data and descriptives}

Confirmed cases of SARS-CoV-2 infections. Estimations are based on daily new confirmed SARS-CoV-2 cases by age group $(5-14,15-34,35-59,60+)$ by all 401 German counties, recorded on the date the local public health authorities became aware of a case. Case numbers are normalized by $100 \mathrm{~K}$ population by county and age group. Data on the observation window from 27 July to 4 October was collected from the publicly available database of the Robert-Koch-Institut (RKI).

Mobility patterns. To account for changes in individual mobility that might contribute to changes in infection patterns, we keep mobility constant by controlling for state-level mobility information from the Google Mobility Reports. The data contain relative stay durations in groceries, parks, home, retail and recreation, transit stations and workplaces. Figure A.1 displays the gradual return of workers to workplaces, retail markets and transit stations and the reduced stay durations in residential areas after the end of summer breaks. 
Table 1: Summary Statistics - confirmed cases of SARS-CoV-2 (by county and day)

\begin{tabular}{|c|c|c|c|c|c|c|c|c|}
\hline & \multicolumn{2}{|c|}{$\begin{array}{c}\text { Full } \\
\text { Period }\end{array}$} & \multicolumn{2}{|c|}{$\begin{array}{c}\text { Before } \\
\text { Summer Break }\end{array}$} & \multicolumn{2}{|c|}{$\begin{array}{c}\text { During } \\
\text { Summer Break }\end{array}$} & \multicolumn{2}{|c|}{$\begin{array}{c}\text { After } \\
\text { Summer Break }\end{array}$} \\
\hline & Mean & $\mathrm{SD}$ & Mean & $\mathrm{SD}$ & Mean & SD & Mean & SD \\
\hline \multicolumn{9}{|l|}{ Age Group } \\
\hline $5-14$ & 12.0 & 22.3 & 1.7 & 5.5 & 8.0 & 15.3 & 27.0 & 30.6 \\
\hline $15-34$ & 8.7 & 12.0 & 1.9 & 3.6 & 9.2 & 11.7 & 14.6 & 14.0 \\
\hline $35-59$ & 4.7 & 6.9 & 0.9 & 1.8 & 4.4 & 6.4 & 8.7 & 8.4 \\
\hline $60+$ & 2.7 & 5.6 & 0.6 & 1.9 & 2.2 & 4.9 & 5.3 & 7.4 \\
\hline All Ages & 6.1 & 8.3 & 1.2 & 1.8 & 5.7 & 7.1 & 11.5 & 10.1 \\
\hline Observations & 45,600 & & 17,100 & & 22,375 & & 22,375 & \\
\hline
\end{tabular}

Note: This table summarizes means and standard deviations of confirmed cases of SARS-CoV-2 normalized by $100 \mathrm{~K}$ population by county and age group. The full observation period covers 13 June 2021-04 October 2021. Source: RKI and Statistical Office.

\subsection{Sample Description}

Table 1 summarizes case numbers over the period of observation by age group and separately for periods before, during and after the summer breaks. Two features are apparent that highlight the difference in the situation of 2021 compared to the situation one year earlier as analyzed in Isphording et al. (2021). While in 2020 case numbers were concentrated in older and vulnerable age groups, now in all periods confirmed cases peak in the youngest age group of 5-14 years. This reflects the impact of increasing vaccination rates. Second, case numbers are on average five times higher than in the same period surrounding the end of summer breaks in 2020. The descriptive data also display the strong dynamics over the summer breaks. While average cases per $100 \mathrm{~K}$ are at just 1.2 cases per day before the summer breaks, they increase to 11.5 cases per $100 \mathrm{~K}$ after the summer breaks. This increase is similar in relative terms over all age groups.9

Figure 2 depicts this dynamic development over the summer breaks. During the aftermath of the third wave in spring, schools were only partially open and case numbers decreased strongly. Yet, coinciding with the beginning of summer breaks, they slowly started to rise again, peaking shortly after the first states had re-opened their schools, and then falling back again. While several reasons may be brought up for this particular development, we will see in the following analysis that school openings with their accompanying regular and mandatory testing seem to have contributed to this pattern.

\footnotetext{
${ }^{9}$ Note that these are daily average cases, different from the "incidence" as a 7-days cumulative sum of cases.
} 


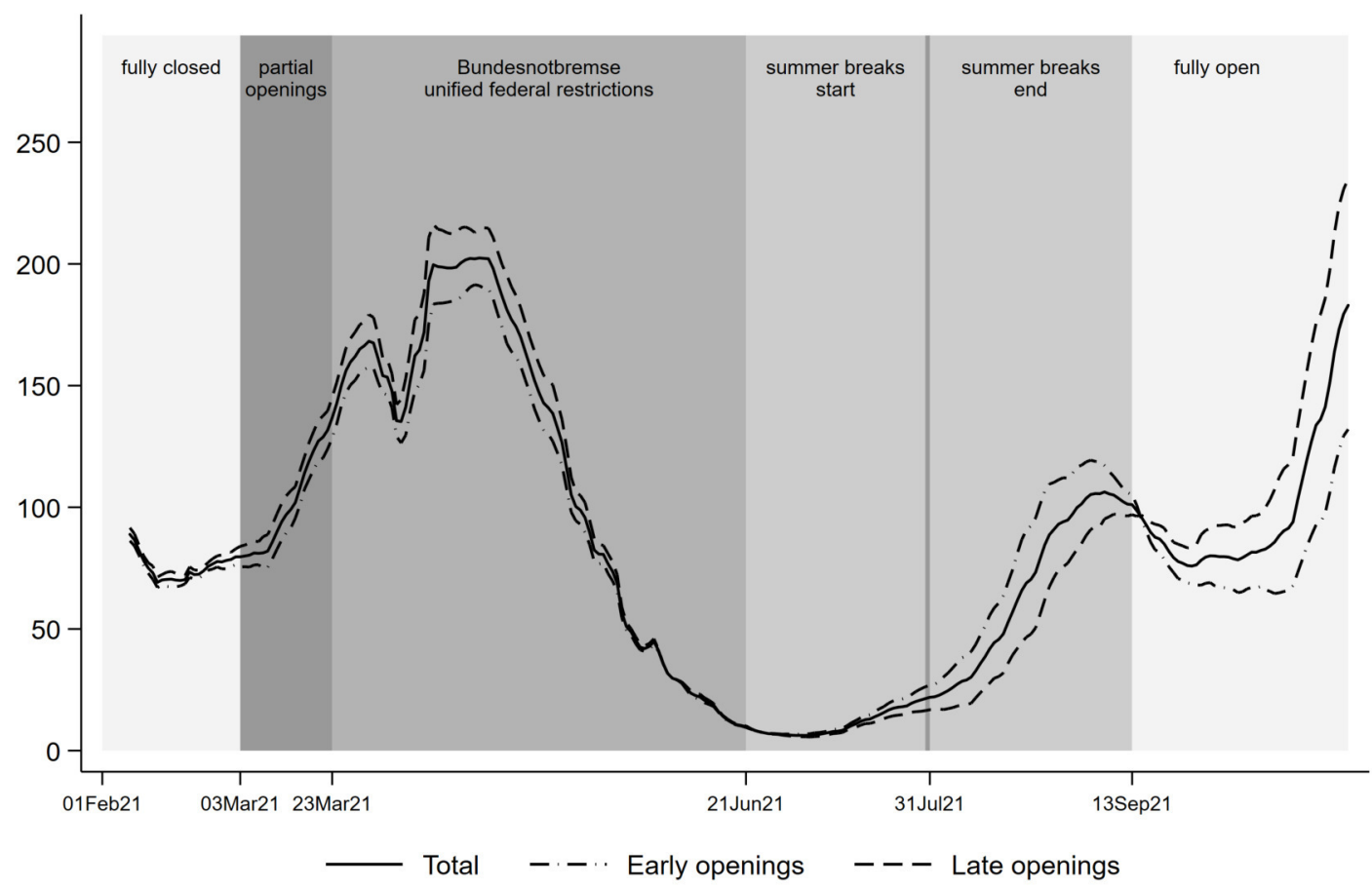

Figure 2: Timeline of COVID-19 Pandemic and School Closures and Openings in Germany

Note: This graph shows the evolution of the number of new confirmed cases per seven days of SARS-CoV-2 infections per 100,000 inhabitants for Germany as a whole (solid line) and by states with summer breaks ending up until 18 August 2021 (early re-opening states) and states with summer breaks ending thereafter (late re-opening states). The shaded areas describe the different phases of school closures and re-openings in Germany. Source: RKI, own presentation.

\subsection{Empirical Strategy}

Following closely earlier estimations by Isphording et al. (2021), we estimate the causal effect of the end of summer breaks and the associated school re-openings on the spread of the pandemic by exploiting the staggered summer break schedule across federal states. We apply an event-study approach that intuitively compares changes in case numbers in re-opening states to changes in case numbers in states that will only re-open in the future.

To interpret this difference as the causal effect of school re-openings, we assume that case numbers in re-opening states would have changed similarly to those in the control states in the unobservable counterfactual situation of schools not being re-opened after summer breaks. While we cannot directly test this assumption, insignificant differences between groups of states indicate a parallel development of case numbers before school re-openings, which strongly supports the causal interpretation of our estimates.

Our empirical model reads:

$$
\mathrm{CoV}_{i t}=\alpha_{i}+\mu_{t}+\sum_{\tau=-15, \tau \neq 0}^{42} \beta_{\tau} \text { SchoolsOpen }_{s(i), t-\tau}+X_{i t}^{\prime} \gamma+\varepsilon_{i t}
$$


The outcome $C o V_{i t}$ describes new confirmed SARS-CoV-2 infections by county $i$ and date $t$, normalized per $100 \mathrm{~K}$ of population. In a robustness check we estimate the same model using the natural logarithm of this number instead. The model is estimated separately by age group. The indicator SchoolsOpen $n_{s(i), t-\tau}$ describes the time lag of day $t$ to the end of summer breaks in county $i$ in state $s$. We consider an effect window of two weeks before and six weeks after the summer breaks 10 All observations before and after the respective statespecific event window are aggregated into bins at the endpoints (Schmidheiny and Siegloch, 2019). We consider $\tau=0$, the last day before the end of summer breaks, as our comparison period 11 County-specific time-invariant confounders such as population structure are captured by county fixed effects $\alpha_{i}$. Time-variant confounders such as the global state of the pandemic and federal restrictions are captured by date-fixed effects $\mu_{t}$. Time-varying variables $X_{i t}$ include mobility patterns by Google Mobility Reports, the county's vaccination rate 14 days ago, and cumulative case numbers over the past 14 days. Standard errors in all estimations are clustered at the federal state level.

\section{Event Study Results}

Figure 3 displays the event study results based on Equation (1) separately by age group. The black solid line connects coefficients that display the difference between re-opening and control states relative to the last day of summer breaks $(t=0){ }^{12}$

For all age groups, we observe a flat pre-trend with coefficients insignificant and close to zero. This flat trend rules out concerns about several sources of potential confounders. First, the flat trends speak against any time-variant influences spuriously correlated with the timing of summer breaks and the pandemic course. Second, flat trends speak against early and late openers being at different stages at the pandemic producing spurious effects of school re-openings. This argument is further supported by the descriptive evidence in Figure 2 which shows that early and late opening states display parallel developments which are set apart by about the average distance in summer break schedules. Third, the flat trends speak against a strong role of travel returnees in producing our result patterns, mechanically increasing case numbers right before the end of summer breaks, which should result in diverging trends right before $t=0$. Taken together, the flat trends suggest that the identification assumption of parallel trends in the absence of school re-openings is plausible.

After schools re-open, we observe for the youngest age group of 5-14 years a significant spike in case numbers. This age group comprises entirely of (pre-)school-aged children, which were rarely tested during summer breaks, and who are now exposed to regular testing during school 13 Accordingly, asymptomatic cases among children were detected and quarantined.

\footnotetext{
${ }^{10}$ We do not prolongue the effect window further to avoid confounding by the then starting autumn holidays.

${ }^{11}$ Here we differ from (Isphording et al. 2021) where the first school day was used as comparison group.

${ }^{12}$ Figure A.2 shows the results when using the natural logarithm of the infection numbers. Qualitative patterns are comparable, yet peaks after school re-openings are less pronounced in the logarithmic specification.

${ }^{13}$ Mandatory schooling in Germany starts in the year a child turns six. The last year of kindergarten/pre-school is free of charge and almost universally attended.
} 
The increased number of cases decreases gradually thereafter, being statistically indistinguishable from the counterfactual after two weeks.

A similar, yet less pronounced spike is also observed for the age group 15-34, which includes both older high-school students as well as young parents 14 After the initial spike, we again observe a gradual decrease in case numbers, accumulating to a significant long-term reduction of up to almost nine cases per $100 \mathrm{~K}$ population.

For the age group 35-59, the initial spike does not materialize. Still, case numbers gradually decrease after school openings, with a long-term decrease of about seven cases per $100 \mathrm{~K}$ population. Finally, for the age group of the most vulnerable of 60 years and older, we still observe a slight reduction after school closures, which remains statistically insignificant.

Taken together, the differing patterns across age groups are in line with schools under mandatory testing being an important measure to screen the population. While participation in indoor activities was largely restricted to vaccinated, formerly infected or tested persons, the demand for rapid testing was declining rapidly over the summer of 2021 as more and more people got vaccinated 15 In this situation, the transition from the summer break setting to an environment with comprehensive and compulsory testing led to the sudden and sustaining detection of asymptomatic infections among school-aged children that would otherwise have remained undetected. Detected cases as well as direct contacts (defined either as seat neighbors or whole classes) were sent into quarantine. Beside testing and quarantining, strict hygiene rules of mask-wearing and venting were in place (see Section 2.2).

\footnotetext{
${ }^{14}$ Unfortunately, age bins are provided by the RKI and do not allow for a sharp distinction between students and older population groups.

${ }^{15}$ Figure A.3 highlights this decrease in demand by Google searches for publicly provided rapid speed testing, the so called "Bürgertests".
} 


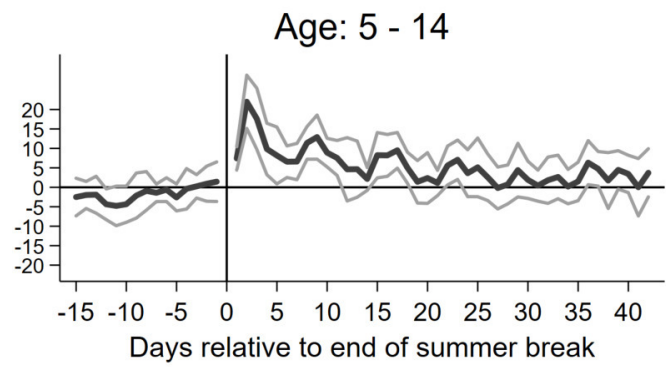

Age: 35 - 59

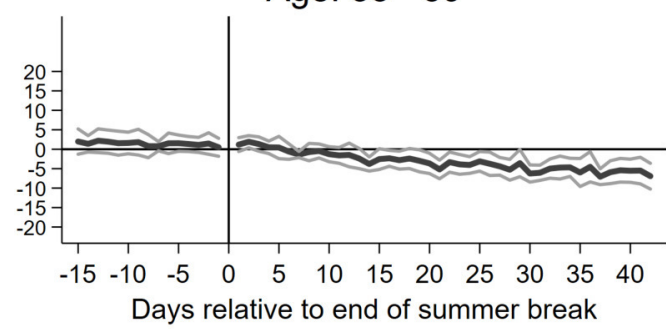

Point estimates

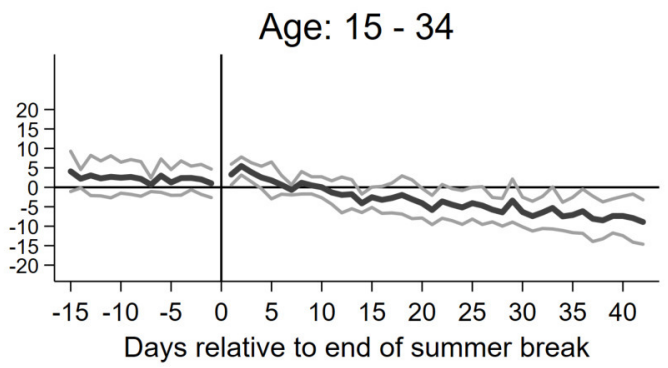

Age: $60+$

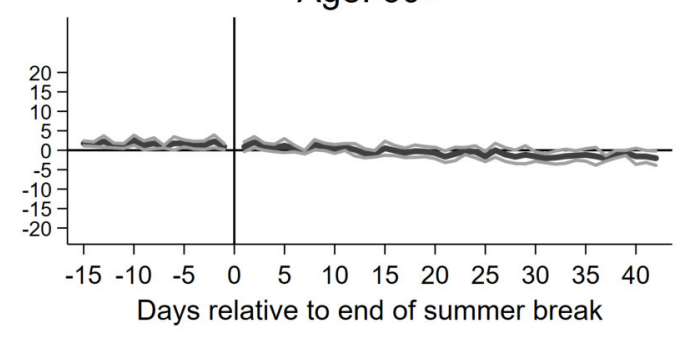

$95 \% \mathrm{Cl}$

Figure 3: The Effect of the End of Summer Breaks on Confirmed Cases by Age Groups

Note: This graph plots the point estimates $\left(\hat{\beta_{\tau}}, \tau \in[-15,42]\right)$ and corresponding $95 \%$ percent confidence intervals of the event study model as defined in Equation (1), separately estimated for cases by age groups 5-14, 15-34, 35-59 and $60+$. The dependent variable is always the daily count of confirmed cases per $100 \mathrm{~K}$ population per county and age group. The vertical line at $\tau=0$ indicates the day before school re-opening. The regressions include fixed effects on the county and day level, as well as time-varying controls for mobility, cumulative case numbers and local vaccination rates. Standard errors are clustered at the federal state level.

\section{Conclusion}

In this study, we apply the methodology of Isphording et al. (2021) to recent data on confirmed cases of SARS-CoV-2 in German counties surrounding the end of summer breaks. Applying an event study model, we provide causal evidence of the isolated role of schools in transmitting the virus.

After summer breaks, schools re-opened under strict hygiene measures and implemented a mandatory rapid testing and quarantining system. Our results confirm the success of this policy. Our estimations suggest that testing and quarantining in schools substantially contributed to uncovering asymptomatic cases that would have remained unobserved during a summer break. The testing led to a pronounced spike in observed cases during the first week after re-opening. Observed cases decreased gradually during the following weeks, being statistically indistinguishable after two weeks. We further observe in prime-aged age groups, comprising of older students and parents, that case numbers steadily decrease below the counterfactual levels that would have prevailed if schools were kept closed. This suggests that early detection of infections by testing school-aged children reduces infections among their parents as well. Case numbers among the most vulnerable age group of ages $60+$ remain unaffected. 
Our results are in line with simulation-based evidence by Mohring et al. (2021) and Gabler et al. (2021) highlighting the important role of population-wide rapid testing. As Mohring et al. (2021) states, only the combination of compulsory schooling and mandatory testing allows for an unfiltered and unbiased look into the state of the pandemic. Our results suggest that increased infections through in-school contacts are more than offset by this surveillance effect of mandatory testing, spilling over into lower case numbers in prime-aged age groups.

We conclude that the trade-off between reducing contacts and losing an important surveillance device has to be taken seriously when re-considering school closures as a nonpharmaceutical intervention under the current circumstances. This is especially true considering the drastic immediate and short-term costs for children and their parents associated with school closures. 


\section{References}

Adda, J. (2016). Economic activity and the spread of viral diseases: Evidence from high frequency data. The Quarterly Journal of Economics 131(2), 891-941.

Alfano, V., S. Ercolano, and L. Cicatiello (2020). A synthetic control method analysis of schools opening and covid-19 outbreak in italy.

Amodio, E., M. Battisti, A. Kourtellos, G. Maggio, and C. M. Maida (2021). Schools opening and covid-19 diffusion: Evidence from geolocalized microdata. Covid Economics 65, 47-77.

Bacher-Hicks, A. and J. Goodman (2021). The covid-19 pandemic is a lousy natural experiment for studying the effects of online learning. EducationNext 21(4).

Bin Nafisah, S. (2018). School closure during novel influenza: a systematic review. Journal of Infection and Public Health, 657-61.

Brookman, S., J. Cook, M. Zucherman, S. Broughton, K. Harman, and A. Gupta (2021). Effect of the new sars-cov-2 variant b. 1.1. 7 on children and young people. The Lancet Child \& Adolescent Health 5(4), e9-e10.

Buntin, M. B. and K. A. Gavulic (2020). Safely reopening schools-learning amid a pandemic. In JAMA Health Forum, Volume 1, pp. e201054-e201054. American Medical Association.

Cauchemez, S., N. M. Ferguson, C. Wachtel, A. Tegnell, G. Saour, B. Duncan, and A. Nicoll (2009, August). Closure of schools during an influenza pandemic. 9(8), 473-481.

Chang, S. L., N. Harding, C. Zachreson, O. M. Cliff, and M. Prokopenko (2020, November). Modelling transmission and control of the COVID-19 pandemic in Australia. 11(1).

Chernozhukov, V., H. Kasahara, and P. Schrimpf (2021, February). The association of opening k-12 schools with the spread of covid-19 in the united states: County-level panel data analysis.

Courtemanche, C. J., A. H. Le, A. Yelowitz, and R. Zimmer (2021). School Reopenings, Mobility, and COVID-19 Spread: Evidence from Texas. Technical report, National Bureau of Economic Research.

Davies, N. G., A. J. Kucharski, R. M. Eggo, A. Gimma, W. J. Edmunds, T. Jombart, K. O'Reilly, A. Endo, J. Hellewell, E. S. Nightingale, B. J. Quilty, C. I. Jarvis, T. W. Russell, P. Klepac, N. I. Bosse, S. Funk, S. Abbott, G. F. Medley, H. Gibbs, C. A. B. Pearson, S. Flasche, M. Jit, S. Clifford, K. Prem, C. Diamond, J. Emery, A. K. Deol, S. R. Procter, K. van Zandvoort, Y. F. Sun, J. D. Munday, A. Rosello, M. Auzenbergs, G. Knight, R. M. G. J. Houben, and Y. Liu (2020, July). Effects of non-pharmaceutical interventions on COVID-19 cases, deaths, and demand for hospital services in the UK: a modelling study. 5(7), e375-e385.

Engzell, P., A. Frey, and M. D. Verhagen (2021, April). Learning loss due to school closures during the COVID-19 pandemic. 118(17), e2022376118.

Ertem, Z., E. M. Schechter-Perkins, E. Oster, P. van den Berg, I. Epshtein, N. Chaiyakunapruk, F. A. Wilson, E. Perencevich, W. B. Pettey, W. Branch-Elliman, et al. (2021). The impact of school opening model on sars-cov-2 community incidence and mortality. Nature Medicine, $1-7$. 
Fontanet, A., R. Grant, L. Tondeur, Y. Madec, L. Grzelak, I. Cailleau, M.-N. Ungeheuer, C. Renaudat, S. F. Pellerin, L. Kuhmel, et al. (2020). Sars-cov-2 infection in primary schools in northern france: A retrospective cohort study in an area of high transmission. MedRxiv.

Fukumoto, K., C. T. McClean, and K. Nakagawa (2021). No causal effect of school closures in japan on the spread of covid-19 in spring 2020. Nature Medicine, 1-9.

Gabler, J., T. Raabe, K. Röhrl, and H.-M. von Gaudecker (2021). The effectiveness of strategies to contain sars-cov-2: Testing, vaccinations, and npis. arXiv preprint arXiv:2106.11129.

Goldhaber, D., S. A. Imberman, K. O. Strunk, B. Hopkins, N. Brown, E. Harbatkin, and T. Kilbride (2021). To what extent does in-person schooling contribute to the spread of COVID-19? Evidence from Michigan and Washington. Technical report, National Bureau of Economic Research.

Harris, D. N., E. Ziedan, and S. Hassig (2021). The effects of school reopenings on COVID-19 hospitalizations. National Center for Research on Education Access and Choice.

Heavey, L., G. Casey, C. Kelly, D. Kelly, and G. McDarby (2020). No evidence of secondary transmission of covid-19 from children attending school in ireland, 2020. Eurosurveillance 25(21), 2000903.

Heggeness, M. L. (2020). Estimating the immediate impact of the covid-19 shock on parental attachment to the labor market and the double bind of mothers. Review of Economics of the Household 18(4), 1053-1078.

Isphording, I. E., M. Lipfert, and N. Pestel (2021). Does re-opening schools contribute to the spread of SARS-CoV-2? Evidence from staggered summer breaks in Germany. Journal of Public Economics 198, 104426.

Jang, Y. and M. Yum (2020). Aggregate and Intergenerational Implications of School Closures: A Quantitative Assessment.

Lee, B., J. P. Hanley, S. Nowak, J. H. Bates, and L. Hébert-Dufresne (2020). Modeling the impact of school reopening on SARS-CoV-2 transmission using contact structure data from Shanghai. BMC Public Health 20(1), 1-9.

Leslie, E. and R. Wilson (2020). Sheltering in place and domestic violence: Evidence from calls for service during covid-19. Journal of Public Economics 189, 104241.

Macartney, K., H. E. Quinn, A. J. Pillsbury, A. Koirala, L. Deng, N. Winkler, A. L. Katelaris, M. V. O'Sullivan, C. Dalton, N. Wood, et al. (2020). Transmission of sars-cov-2 in australian educational settings: a prospective cohort study. The Lancet Child \& Adolescent Health 4(11), 807-816.

Mohring, J., M. Burger, R. F. Bler, J. Fiedler, N. Leithäuser, J. Schneider, M. Speckert, and J. Wlazlo (2021). Starker effekt von schnelltests. eine analyse mit hilfe der epidemsesoftware. Technical report, Fraunhofer Institut f $\tilde{A} \frac{1}{4} r$ Techno- und Wirtschaftsmathemathik ITWM.

Panovska-Griffiths, J., C. C. Kerr, R. M. Stuart, D. Mistry, D. J. Klein, R. M. Viner, and C. Bonell (2020, November). Determining the optimal strategy for reopening schools, the impact of test and trace interventions, and the risk of occurrence of a second COVID-19 epidemic wave in the UK: a modelling study. $\underline{4}(11), 817-827$. 
Schmidheiny, K. and S. Siegloch (2019). On event study designs and distributed-lag models: Equivalence, generalization and practical implications.

Stein-Zamir, C., N. Abramson, H. Shoob, E. Libal, M. Bitan, T. Cardash, R. Cayam, and I. Miskin (2020). A large COVID-19 outbreak in a high school 10 days after schools' reopening, Israel, May 2020. Eurosurveillance 25(29), 2001352.

Tang, P., M. Hasan, H. Chemaitelly, and et al. (2021). BNT162b2 and mRNA-1273 COVID-19 vaccine effectiveness against the SARS-CoV-2 Delta variant in Qatar. Nature Medicine.

Viner, R. M., S. Russell, R. Saulle, H. Croker, C. Stansfield, J. Packer, D. Nicholls, A.-L. Goddings, C. Bonell, L. Hudson, et al. (2021). Impacts of school closures on physical and mental health of children and young people: a systematic review. MedRxiv.

Vlachos, J., E. Hertegård, and H. B. Svaleryd (2021). The effects of school closures on SARS-CoV-2 among parents and teachers. Proceedings of the National Academy of Sciences $118(9)$.

von Bismarck-Osten, C., K. Borusyak, and U. Schönberg (2021). The role of schools in transmission of the sars-cov-2 virus: Quasi-experimental evidence from germany. Technical report, cemmap working paper.

Walsh, S., A. Chowdhury, V. Braithwaite, S. Russell, J. M. Birch, J. L. Ward, C. Waddington, C. Brayne, C. Bonell, R. M. Viner, and O. T. Mytton (2021, August). Do school closures and school reopenings affect community transmission of COVID-19? a systematic review of observational studies. $\underline{11}(8)$, e053371.

Werner, K. and L. Woessmann (2021). The legacy of covid-19 in education. IZA Discussion Paper No. 14796.

Willyard, C. (2021). Covid and schools: the evidence for reopening safely. Nature 595(7866), 164-167. 


\section{A Appendix Figures and Tables}

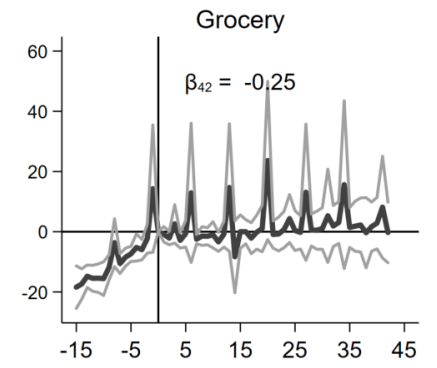

Days relative to end of summer break

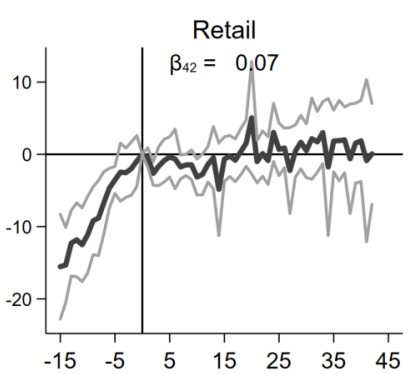

Days relative to end of summer break

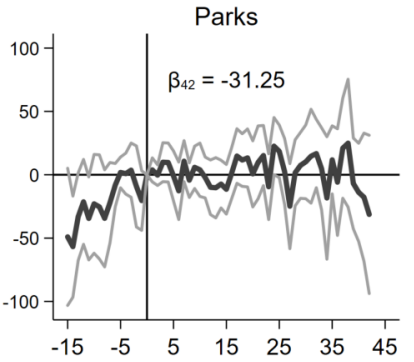

Days relative to end of summer break

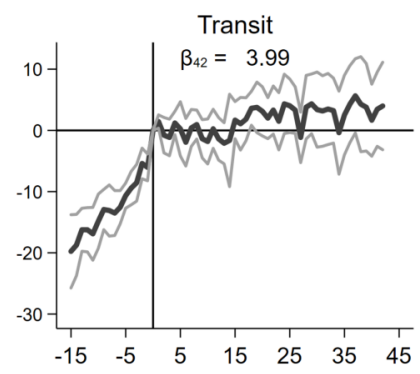

Days relative to end of summer break

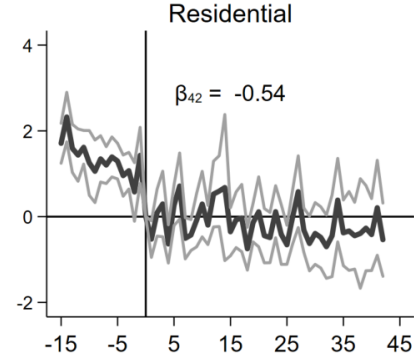

Days relative to end of summer break

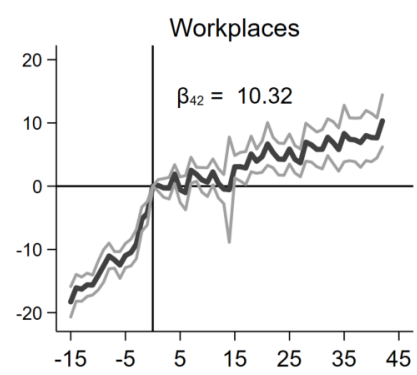

Days relative to end of summer break

Figure A.1: The Effect of the End of Summer Breaks on Mobility Patterns

Note: This graph plots the point estimates $\left(\hat{\beta_{\tau}}, \tau \in[-15,42]\right)$ and corresponding $95 \%$ percent confidence intervals of the event study model as defined in Equation (1). The dependent variables is the percentage change in mobility compared to a baseline period. Mobility measures are based on Google Mobility Reports. The vertical line at $\tau=0$ indicates the day before school re-opening. The regressions include fixed effects on the state by day-of-the-week and day level. Standard errors are clustered at the federal state level. 
Age: 5 - 14

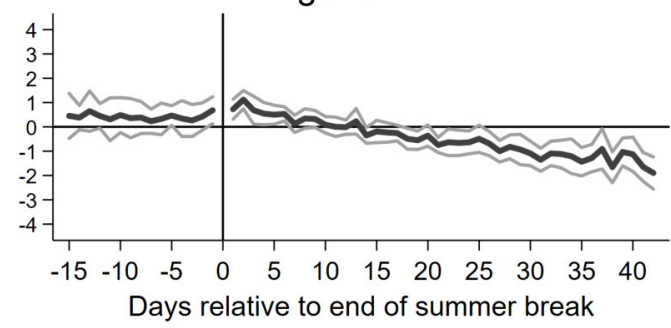

Age: $35-59$

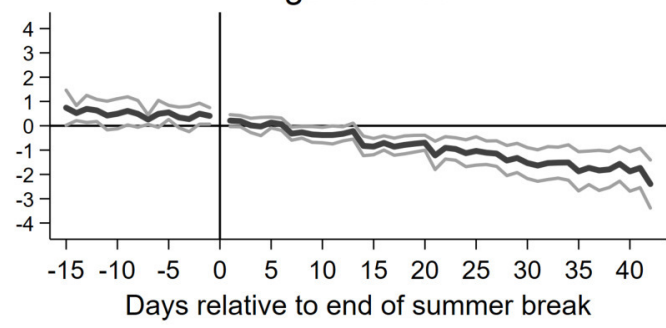

Age: 15 - 34

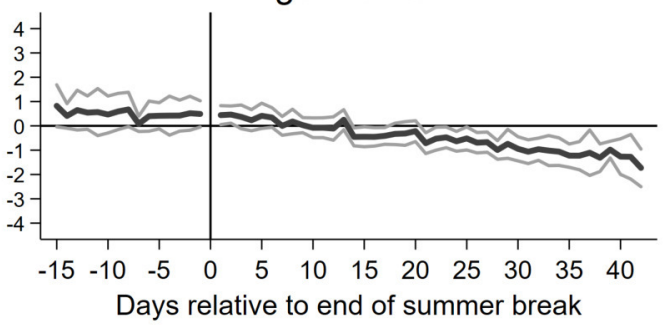

Age: $60+$

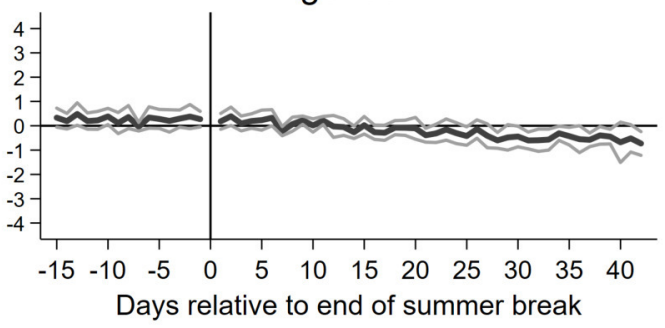

$95 \% \mathrm{Cl}$

Figure A.2: The Effect of the End of Summer Breaks on Confirmed Cases by Age Groups, logarithmic specification

Note: This graph plots the point estimates $\left(\hat{\beta_{\tau}}, \tau \in[-15,42]\right)$ and corresponding $95 \%$ percent confidence intervals of the event study model as defined in Equation (1), with separately estimated by age groups 5-14, 15-34, 35-59 and $60+$. The dependent variable is always the logarithm of the daily count of confirmed cases per $100 \mathrm{~K}$ population per county and age group. The vertical line at $\tau=0$ indicates the day before school re-opening. The regressions include fixed effects on the county and day level, as well as time-varying controls for mobility, cumulative case numbers and local vaccination rates. Standard errors are clustered at the federal state level. 


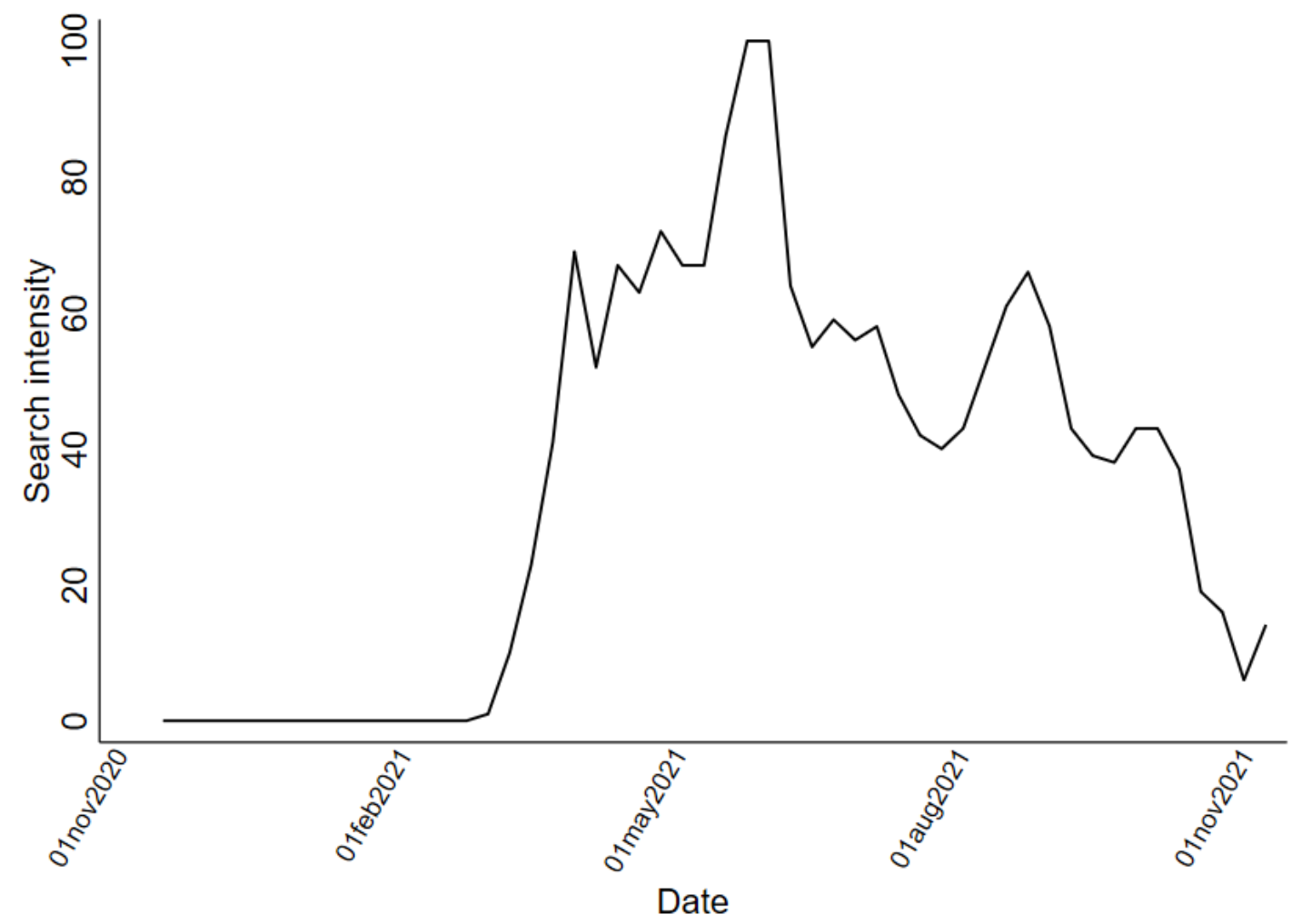

Figure A.3: Search intensity for publicly provided Corona tests ("Bürgertests")

Note: This graph plots relative search intensity for for publicly provided Corona tests ("Bürgertests") based on data collected from Google Trends. All numbers are interpreted relatively to the peak search intensity in late May. 